\title{
Research on the Situation and Problems of Government Internet Management under the Ruling of Law
}

\author{
Yang Yang*, Yijie Tang \\ Southwest University, Chongqing, China \\ Email: "yangkent78@qq.com
}

Received 24 November 2015; accepted 18 December 2015; published 22 December 2015

Copyright (C) 2015 by authors and Scientific Research Publishing Inc.

This work is licensed under the Creative Commons Attribution International License (CC BY). http://creativecommons.org/licenses/by/4.0/

(c) (i) Open Access

\begin{abstract}
Owing to the development of Internet, there are some new features for the current situation of contemporary government management, such as, the immediacy and rapidity of government collecting information, as well as the corresponding breadth and effectiveness of government announcing information. How does the government strengthen their control force for information throughout refining itself to manage more effectively in the age of Interne? The countermeasures can be found only by analyzing the problem, so this paper mainly analyzes its situation and problems. Through analyzing government's situations and problems, it shows that the concept of rule of law is imperfect, the legislation is not scientific and not projected, there are loopholes in enforcing the law, there is non-supervision during the process of enforcing the law and the supervision should be strengthened in justice.
\end{abstract}

\section{Keywords}

Government Internet Management, Rule by Law, Situation and Problems

\section{Introduction}

Along with the coming of the network times, it makes our country enter the reform era of government management. The technology of Internet brings new approaches and opportunities to government management, which means a new capable tool devoting to modernize transformation of governance mode. It is a new idea for government internet management being under ruling by law to respond to the requirements of the social development. Network is as a new way for the peoples' political participation, government internet management under

${ }^{*}$ Corresponding author. 
ruling by law is a kind of tool of effective political participation to balance the interests of different interests. It is not only favored by citizens, but also more conducive to improve the government's ability of strategic management to promote the sustainable development of government governance way. But there are many problems in the government network management in the practice. Its effect is not very well to promote the government and the people's interaction and to make innovation the government management. Based on it, this paper tries to analyze the current situation of government management under the condition of the contemporary network technology through the multiple dimensions, at the same time, combing with the rule of law background to explore the reasons for the current management difficulties, and the corresponding countermeasures would be effectively found out.

\section{The Situation of Contemporary Government Management}

From the government's point, there are three advantages of the network technique growth. Primarily, the immediacy and rapidity of government collecting information enable itself to know the citizens psychology and trend. As for government, gathering and integrating the information swiftly through the network changes the traditional pattern of information acquisition. Thanks to the more direct and unimpeded channel of information collection made by Internet, the phenomenon of information twist, interruption or distortion due to some artificial factors in conventional process reduces, which means that central government get more authentic and complete information eventually. The real messages offer government an actual condition of construction and improvement for public culture, enabling it to hold the right developing orientation of public culture, what's more, adjusting the policy according to the present public culture situation as well. Additionally, it is the rapidity, directness and breadth of government announcing information. The structure of state in China is unitary system. The information was previously given by the center to provinces, and then to cities, counties, and towns, the most basic grass-roots level, were supposed to implement the policy, which enlarged the rate of information content loss and information distortion, also easing the pace of information transmission. But now the Internet accelerates the speed of message passing, as a result, the center government is able to deliver the wanted information more swiftly and immediately (Jiang, 2012). Simultaneously, owing to the expanding of Internet coverage, messages can overcome the natural factors like geology and land-forms to transfer to citizens. Only if the citizens know about the government's path, principle and policy accurately, government activities would be launched more efficiently and the administration's intervention to public culture construction would be realized more effectively. Thus, it is urgent for government to refine itself to strengthen the control force for information in order to improve the governing capacity efficacious throughout the Internet.

\section{The Problems of Government Management in the Age of Internet}

With the era background of comprehensively promoting the rule of law, it brings some challenges to government management. The problems are mainly shown in following five points.

Firstly, it is the weak awareness of ruling by law. For the government, Chinese Internet field unduly relies on morality adjudication instead of ruling of law. For the citizens, the idea of ruling of law in present society has not pervaded in Internet field yet, in other words, most citizens haven't connected the thought of governed by law to the network world, which is a big challenge to network order. Although the characteristics of immediacy and rapidity that Internet possesses offer enormous benefit to citizens life, it has some adverse impact. From those incidents of disordered network in recent years, we can witness that morality adjudication was the main means to control the Internet order, nevertheless, leading reverse consequence sometimes (Dong \& Wang, 2011). In the age of network, the virility makes everyone to be unrecognized, citizen identity invented and digitized. In this time, the network world was filled with goodwill and illness as well. The virility of Internet offer the opportunity for the conscientious people to attain its target by using the consciousness of following blindly, misanthropic and wealth envy through the means of network planning and event organizing. The outcome is that citizens consider their words and behaviors satisfying its fancied so-called moral which is the right standard. Without the limit of law, wrong morality may push the network group incident to vicious trend, causing some phenomenon that disturb the normal order of Internet, breed bad society effect and damage the security of state, such as network foul hype, malicious charging public official as well as the transmission of net rumor. If the condition of Internet like that was expanded constantly instead of being prevented in time, it is possible to emerge adverse atmosphere in the whole society due to the Internet, influencing the governance of government. 
Secondarily, when the legislature built the laws there is none of accurate plan. From the time that network sprung up, the American state had already recognized that reasonable regulations for Internet running would bring various benefit to their country, however, our government seems not to be aware of the significance of legislative system in network. The authorities are always in a condition of that establishing laws is for the sake of replying the problems emerged, taking measures only if the troubles come. Since there is no perspective and well-planned point during the legislative process, problems appear constantly. For instance, in the era of network, some of the government's specific administrative behavior has caused a loss to citizen's individual virtual property in Internet. In the incident involved state compensation, as for the definition and estimation of online virtual property, also due to the specific attributes of that, may emerge the problem of the great discrepancy in the valuation of fictitious wealth in a period of time. There still exists a huge loophole in legislation in the new network circumstance, completely not adapting the development of that. The government has not nipped in the bud yet, facing endless unknown challenges in the Internet field. At the same time, legislative system without planning makes government cannot play its continuous, stable, and correct influence. As a consequence, except laws the other uncertain factors like extraneous values, religious belief and conventional morality will enlarge its effect to people in the domain of network. If this weakness is used by some lawbreaker, the online society will be disordered, threatening the government management force.

Thirdly, there are omissions in the foundation of executing the law. The current policy and regulation in network governance are inadequate to provide sufficient authority for executing the law. To begin with, the current policy and regulation in China in this field are too macroscopic and unpractical with some legislative deficiency in law. There have been several regulations carried out since 1980s such as the RPOC Copyright Law, Measures for the Administration of Internet Information Service, the Regulations for the Administration of Business Sites of Internet Access Services, the Internet Culture Management Interim Provisions, and Regulations for the Protection of Information Network Transmission Right. However, these regulations focus only on some specific field and China hasn't carried out appropriate regulations aiming at every aspect of the network by far; and thus resulting in legislative deficiency in network. Moreover, the current policies and regulations in network are rather simple and not detailed enough; different regulations have almost the same framework. In this case, not only are we unable to analyze specific issues depending on the situation, but the authority of policy and regulation is also diminished. For example, it is mentioned in Measures for the Administration of Internet Information Service, the Regulations for the Administration of Business Sites of Internet Access Services and the Internet Culture Management Interim Provisions to forbid the behavior that is against the basic principles regulated by constitution or that is banned by the laws and administrative regulations. Rules like this are way too broad and macroscopic for non-professionals to understand, and even the professional who can fully understand can't delimit a precise scope; this therefore gives rise to an obstacle to executing the law.

Fourthly, the supervision in the act of law enforcement is weak in operation. The faultiness of supervision in network governance has situated policy and regulation of this field in a low-efficiency condition. There are two reasons for it. First is that the administrative interpretation of policy and regulation is not thorough enough. As is mentioned above, the content of policy and regulation is sometimes too sketchy for both non-professionals and professionals to understand. For example, the measures of site security, information security and users information security that is mentioned in article 6 in Measures for the Administration of Internet Information Service hasn't been given explanation; and it makes a number of people unable to understand what site security, information security and user's information security measures are. Furthermore, the supervision system of law enforcement has not yet been established, which will keep the law enforcement officials from getting information in time and sending relevant information to the decision center. There are two difficulties in establishing a perfect supervision system. One is that the government itself is immature in information acquisition: firstly, the openness and virility of network requires government's high technique in network supervision and if efficient supervision is missed, valid information will not be provided; secondly, lacking a perfect supervision system, government will fail to master the needed information in all directions. The other lies in the absence of supervisor of law enforcement. This is because firstly the fact that the openness of network is connected with freedom of expression makes some citizens have extreme tolerance towards speech on the Internet, which diminishes the subjective power of citizens during the supervision; secondly, the People's Congress, the People's Political Consultative Conference, non-governmental organizations and other supervision subjects have not given a full play, which causes difficulty in decision center getting information and thus makes the supervision of law enforcement a vulnerable spot, doing harm to the efficiency of policy and regulation of the whole network field 
(Luo, 2012).

Fifthly, the judicial post supervision shall be improved. In the past, the network law enforcement in China involves many departments and when it comes to law enforcement of relevant department, the law doesn't formulate detailed steps. As a result of it, when there is interest, many departments will get involve, causing a huge mess in managing and each department doing things in its own way. Meanwhile, when it's unprofitable, a collective silence will occur in every department, and thus a vacuum in supervision arises. At this time the law doesn't have and is unable to supervise the process of enforcing it. Although 4th plenary session of 18th CPC Central Committee has put forward the regulation to trace accountability when leaders intervene in the judicial process and interfere in conducting specific cases, it's impossible to bring this problem under permanent control if function division in administrative department is not stipulated by law. In addition, supervision by public opinions going too far will influence the adjudication of the judicial office, causing tyranny of the majority and injustices. Socrates once told Kriton, that when someone is in serious training, he should be awed by the criticism raised by qualified people, be open to their praise, and be indifferent to the opinions of the vulgar. Instead of declaring that government does not mind what the populace's opinions, this sentence elucidates that not every person is professional. Once the citizens follow the crowd blindly, and the public culture which may becloud the judicial authority takes shape, it's likely that tyranny of the majority comes into being. All of these have influenced the independence of judiciary (Huang \& Xue, 2011).

\section{Conclusion}

Above all, finding the problems, then we can take corresponding measures. With the era background of promoting the rule of law, government is supposed to insist the concept of "scientific legislation, strict enforcement, judicial justice, national compliance”, comprehensively performing its functions according to the regulation. Meanwhile, combining the advanced network technique is indispensable to realize the modernization of governance ability and level.

\section{References}

Jiang, X. M. (2012). Analysis of the Characteristics and Development for the Current Public Opinion Supervision of Chinese Network. Journal of Statistics Management, 6, 139-140.

Dong, T., \& Wang, J. L. (2011). The Study Rout, Issue and Perspective of the Network Group Events. Journal of Modern Communication, 8, 23-28.

Luo, B. (2012). Study of the Rule of Law for the Government Governance at the Time of Network (pp. 15-18). Xiangtan: Xiangtan University.

Huang, W., \& Xue, F. (2011). Analysis of the System of the Chinese Judicial Independence. Journal of Legal System and Society, 14, 120-121. 